\title{
Article \\ Efficient Delivery of Hydrophilic Small Molecules to Retinal Cell Lines Using Gel Core-Containing Solid Lipid Nanoparticles
}

\author{
Li Huang ${ }^{1, \dagger}$, Erico Himawan ${ }^{2, *,+} \oplus$, Soumaya Belhadj ${ }^{3}$, Raúl Oswaldo Pérez García ${ }^{4}$, François Paquet Durand ${ }^{3}$, \\ Nicolaas Schipper ${ }^{4}$, Matej Buzgo ${ }^{2, \ddagger}$, Aiva Simaite ${ }^{2 \mathbb{D}}$ and Valeria Marigo ${ }^{1,5, *}$
}

1 Department of Life Sciences, University of Modena and Reggio Emilia, 41125 Modena, Italy; li.huang@unimore.it

2 Research and Development Department, InoCure s.r.o, 11000 Prague, Czech Republic; buzgo@labdemo.cz (M.B.); aiva.simaite@gmail.com (A.S.)

3 Cell Death Mechanism Group, Institute for Ophthalmic Research, University of Tuebingen, 72076 Tuebingen, Germany; soumaya.belhadj@uni-tuebingen.de (S.B.); francois.paquet-durand@klinikum.uni-tuebingen.de (F.P.D.)

4 Division Bioeconomy and Health, Chemical Process and Pharmaceutical Development, RISE Research Institutes of Sweden, Forskargatan 18, 15136 Södertälje, Sweden; oswaldo.perez@ri.se (R.O.P.G.); nicolaas.schipper@ri.se (N.S.)

5 Center for Neuroscience and Neurotechnology, Via Campi 287, 41125 Modena, Italy

* Correspondence: erico.himawan@gmail.com (E.H.); vmarigo@unimore.it (V.M.)

+ These authors contributed equally to this work.

$\ddagger$ Present address: BIOFABICS-3D Biotissue Analogues, 4200-135 Porto, Portugal.

\section{check for}

updates

Citation: Huang, L.; Himawan, E.;

Belhadj, S.; Pérez García, R.O.; Paquet Durand, F.; Schipper, N.; Buzgo, M.; Simaite, A.; Marigo, V. Efficient Delivery of Hydrophilic Small Molecules to Retinal Cell Lines Using Gel Core-Containing Solid Lipid

Nanoparticles. Pharmaceutics 2022, 14, 74. https://doi.org/10.3390/ pharmaceutics 14010074

Academic Editor: Hwankyu Lee

Received: 19 November 2021

Accepted: 26 December 2021

Published: 28 December 2021

Publisher's Note: MDPI stays neutral with regard to jurisdictional claims in published maps and institutional affiliations.

Copyright: (C) 2021 by the authors. Licensee MDPI, Basel, Switzerland. This article is an open access article distributed under the terms and conditions of the Creative Commons Attribution (CC BY) license (https:// creativecommons.org/licenses/by/ $4.0 /)$.

\begin{abstract}
In this study, we developed a novel solid lipid nanoparticle (SLN) formulation for drug delivery of small hydrophilic cargos to the retina. The new formulation, based on a gel core and composite shell, allowed up to two-fold increase in the encapsulation efficiency. The type of hydrophobic polyester used in the composite shell mixture affected the particle surface charge, colloidal stability, and cell internalization profile. We validated SLNs as a drug delivery system by performing the encapsulation of a hydrophilic neuroprotective cyclic guanosine monophosphate analog, previously demonstrated to hold retinoprotective properties, and the best formulation resulted in particles with a size of $\pm 250 \mathrm{~nm}$, anionic charge $>-20 \mathrm{mV}$, and an encapsulation efficiency of $\pm 60 \%$, criteria that are suitable for retinal delivery. In vitro studies using the ARPE-19 and 661W retinal cell lines revealed the relatively low toxicity of SLNs, even when a high particle concentration was used. More importantly, SLN could be taken up by the cells and the release of the hydrophilic cargo in the cytoplasm was visually demonstrated. These findings suggest that the newly developed SLN with a gel core and composite polymer/lipid shell holds all the characteristics suitable for the drug delivery of small hydrophilic active molecules into retinal cells.
\end{abstract}

Keywords: drug delivery system; thermoresponsive polymer; rod photoreceptor; retinal pigment epithelium

\section{Introduction}

Retinal degeneration is a disease condition characterized by the progressive loss of highly differentiated cells within the neurosensory retina, such as photoreceptors, or the retinal pigment epithelium (RPE). This condition is commonly found in patients with diabetic retinopathy [1], age-related macular degeneration [2], and hereditary retinal degeneration [3]. Disease associated with retinal degeneration constitutes an important health challenge that severely affects the quality of life of patients and has a significant socioeconomic impact [4]. Recently, hydrophilic cargos, like nucleic acids [5] or cGMP analog [6], has attracted major interest for the development of new retinal disease treatments. These hydrophilic cargos may require encapsulation in a nanocarrier to reach their intracellular 
targets. However, low encapsulation efficiency, undesired leakage, or initial burst release are common issues affecting nanoparticulate drug delivery system (DDS) development [7].

Drug delivery to the retina is also notoriously difficult due to the presence of several biological barriers [8,9]. In current clinical practice, intravitreal injections are routinely used to administer treatments to the retina. This route allows the DDS to bypass several ocular barriers, such as the corneal epithelium, the conjunctiva, and the sclera, while the vitreous and internal limiting membrane (ILM) still need to be crossed. The main considerations of DDS formulation in intravitreal injection routes are the particle size, surface charge, and the functional materials used to enhance intracellular delivery. The vitreous has a gel-like network structure with a pore size expected to be in the range of $500 \mathrm{~nm}$ [10]. Small drugs, proteins, and nanoparticles may diffuse through the vitreous [10,11]. A negatively charged surface and size below $500 \mathrm{~nm}$ are preferred qualities for a DDS because these features may improve particle mobility $[11,12]$. When the drug requires intracellular targeting within the retina, barriers at the level of the plasma membrane will limit its diffusion, especially for hydrophilic molecules [13]. A DDS can help the delivery of the drug [8] and nanoparticles composed of material that enhances endocytosis, such as solid lipid nanoparticles (SLN), will likely improve the entrance of the active compound into the target cells $[9,14,15]$.

The water-in-oil-in-water $\left(\mathrm{W}_{1} / \mathrm{O} / \mathrm{W}_{2}\right)$ emulsion method is generally used to prepare lipid-based particles to encapsulate small hydrophilic molecules. Lipid-based particles obtained via this method, such as liposomes, often have a low encapsulation efficiency due to leakage from the core during preparation [16]. Other lipid-based particles, like conventional SLNs, have limited space for the uptake of hydrophilic molecules [17] and compounds may be expelled following the polymorphic transition of the structure during storage [18]. To accommodate larger amounts of active molecules in the core of lipidbased particles and prevent their premature release, the addition of a thermoresponsive gel core [19] or of micelles [20,21] was shown to improve the encapsulation of the hydrophilic cargo. Unfortunately, these studies used a large macromolecule (i.e., protein) as cargo and the suitability for the direct translation of this DDS to the delivery of small hydrophilic molecules into retinal cells is not readily available.

In this study, we evaluated the potential to adapt and modify SLN formulations originally intended for holding hydrophilic macromolecules as a suitable DDS for delivering small hydrophilic molecules into retinal cells. First, we investigated the effect of adding a thermoresponsive gel core inside the SLN in terms of encapsulation efficiency. We also investigated the effect of adding a hydrophobic polyester to the SLN shell in regard to DDS size, surface charge, and polydispersity. The small size, negative surface charge, stability, encapsulation efficiency, low toxicity, and internalization capability in retinal cells in vitro support the possible use of such SLNs for intravitreal delivery.

\section{Materials and Methods}

\subsection{Materials}

Poloxamer 407 (Sigma Aldrich, Prague, Czech Republic), poloxamer 188 (Applichem, Prague, Czech Republic), rhodamine B (RhoB; Sigma Aldrich, Prague, Czech Republic), Rp-8-Br-PET-cGMPS, also known as CN03 (provided by Research Institute of Sweden), glycerol tripalmitate (GTP; Alfa Aesar, Kandel, Germany), soybean lecithin (LCT; VWR, Prague, Czech Republic), stearic acid (SA; BASF, Prague, Czech Republic), 50/50 DL-lactide/glycolide copolymer (PLGA; Corbion, Amsterdam, Netherlands), poly- $\varepsilon$-caprolactone $14 \mathrm{kDa}$ (PCL; Sigma Aldrich, Prague, Czech Republic), 8-aminonaphthalene-1,3,6-trisulfonic acid disodium salt (ANTS; Biotium, Prague, Czech Republic), p-xylene-bis-pyridinium bromide (DPX; Biotium, Prague, Czech Republic), dichloromethane (VWR, Prague, Czech Republic), deionized water (VWR, Prague, Czech Republic), human adult retinal pigment epithelial cells (ARPE-19 cell, ATCC), 661W cell (generously provided by Dr. Muayyad Al-Ubaidi, University of Oklahoma), Dulbecco's modified Eagle's medium and Ham's F12 nutrient mixture (DMEM/F12; Gibco, Rodano, Italy), low glucose (1 mg/mL) Dulbecco's modified Eagle's medium (DMEM; Gibco, Rodano, Italy), fetal bovine serum (FBS; Gibco, 
Rodano, Italy), glutamine (Sigma Aldrich, Milan, Italy), penicillin-streptomycin (Sigma Aldrich, Milan, Italy), Accutase ${ }^{\circledR}$ solution (Sigma-Aldrich, Milan, Italy), paraformaldehyde (PFA; Sigma Aldrich, Milan, Italy), anti-Zonula occludens-1 (ZO-1) antibody (Invitrogen, Rodano, Italy), goat anti-rabbit secondary antibody (Life Technologies, Rodano, Italy), 4',6-diamidino-2-phenylindole, dihydrochloride (DAPI; Sigma Aldrich, Milan, Italy), colorimetric methyl-thiazolyl diphenyl-tetrazolium bromide (MTT; Sigma Aldrich, Milan, Italy). All purchased materials were used as received.

\subsection{Nanoparticle Synthesis}

The SLN formulation is illustrated in Figure 1A. A stock solution for $\mathrm{W}_{1}$-phase without gel core was prepared by dissolving RhoB in deionized water to reach $10 \mathrm{mg} / \mathrm{mL}$ concentration. For $\mathrm{W}_{1}$-phase stock with gel core, poloxamer 407 was added to the RhoB solution to reach $40 \% \mathrm{w} / \mathrm{v}$. To ensure complete dissolution, the poloxamer 407 solution was dissolved at $4{ }^{\circ} \mathrm{C}$ for $48 \mathrm{~h}$. The $\mathrm{W}_{2}$-phase stock solution was prepared by dissolving poloxamer 188 in deionized water to reach $2 \% w / v$ concentration. The O-phase solution was prepared by dissolving GTP, LCT, SA, and PCL or PLGA in $1 \mathrm{~mL}$ of dichloromethane according to different formulation codes listed in Table S1. Finally, for the preparation of blank and drug-loaded particles, deionized water or $\mathrm{CNO} 3$ was added, respectively, in the $\mathrm{W}_{1}$-phase instead of RhoB. Similarly, for release assays of the compound from SLN inside the cell, ANTS $(25 \mu \mathrm{M})$ and DPX $(90 \mu \mathrm{M})$ were co-encapsulated in the $\mathrm{W}_{1}$-phase instead of RhoB. ANTS and DPX, which form a fluorescence tracer and quencher pair, were chosen based on previously published studies [22].
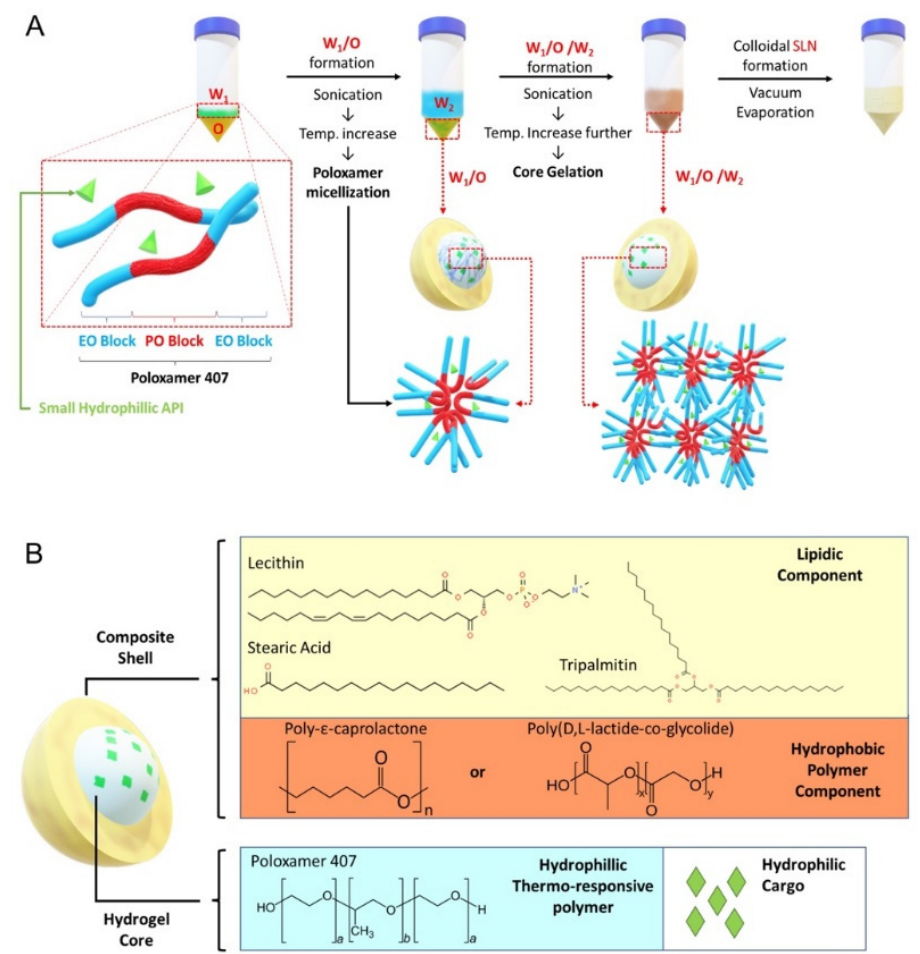

Figure 1. Solid lipid nanoparticle (SLN) formulation. (A) Core gelation procedure of thermoresponsive poloxamer 407 and procedure for SLN generation with a size range of 200-250 nm. (B) Schematic representation of SLN containing gel core and composite shell.

The synthesis was performed by adding $200 \mu \mathrm{L}$ of $\mathrm{W}_{1}$-phase stock solution kept at $4-7^{\circ} \mathrm{C}$, using an ice bath, to $1 \mathrm{~mL}$ of O-phase solution, followed by sonication with a Q55 ultrasound probe (Qsonica, Newton, CT, USA) at 30\% amplitude for $60 \mathrm{~s}$ without a pulse to form the primary $\mathrm{W}_{1} / \mathrm{O}$ emulsion. Then, $4.8 \mathrm{~mL}$ of $\mathrm{W}_{2}$-phase solution was added into the primary emulsion and sonicated to form $\mathrm{W}_{1} / \mathrm{O} / \mathrm{W}_{2}$ emulsion (amplitude: $40 \%$ for $10 \mathrm{~s}$ 
followed by 20 s at $20 \%$ amplitude without a pulse). The solution was further diluted with $10 \mathrm{~mL}$ of $\mathrm{W}_{2}$-phase solution followed by sonication (amplitude: $20 \%$ for $30 \mathrm{~s}$ without a pulse). The organic solvent was then removed by vacuum evaporation (P: $650 \mathrm{mmHg}$ ) at room temperature for $20 \mathrm{~min}$ to form the nanoparticles. The resulting colloidal solution was stirred for $4 \mathrm{~h}$ to ensure complete removal of dichloromethane.

\subsection{Physicochemical Characterization}

\subsubsection{Dynamic Laser Scattering}

Particle size distribution and hydrodynamic diameter were measured using NanoPhox DLS equipment (Sympatec $\mathrm{GmbH}$, Clausthal-Zellerfeld, Germany). Before the measurement, concentrated particle solutions were diluted 5 times using $2 \% w / v$ poloxamer 188 solutions. The analyses were performed using a non-negative least square (NNLS) algorithm integrated in Windox 5 software (Sympatec GmbH, Clausthal-Zellerfeld, Germany). Viscosity of the solutions was calibrated and validated using polystyrene bead standards. For each sample, the measurement was repeated 3 times, each lasting $200 \mathrm{~s}$.

\subsubsection{Zeta Potential}

The zeta potential of the particles was measured by Zetasizer equipment (Malvern Panalytical Ltd., Malvern, UK). Samples were diluted 5 times using $10 \mathrm{mM}$ phosphate buffer, pH 7.4. For each sample, the measurement was repeated 3 times.

\subsubsection{Morphological Analysis}

SLN solutions, as described in Table S1, were synthesized without hydrophilic cargo (i.e., blank particles) and analyzed using a transmission electron microscope (TEM). The colloidal nanoparticle solutions were stained with $7 \%(w / v)$ phosphotungstic acid for negative contrast. The morphological characterization of the particle was performed at a TEM acceleration voltage of $120 \mathrm{kV}$.

\subsubsection{Encapsulation Efficiency}

Encapsulation efficiency (EE) was measured using an indirect method in which the amount of unencapsulated cargo outside the particles was measured. Sample solutions were filtered using a $100 \mathrm{kDa}$ microcentrifuge membrane filter (Sartorius, Brno, Czech Republic) $(3 \times 5 \mathrm{~min}$, at $5000 \times \mathrm{g})$. The filtrate was collected and the amount of cargo was quantified using equation 1 . As there may be some loss of W1-Phase in the pipette tips during synthesis, cargo loss was quantified to avoid overestimation of encapsulation efficiency.

$$
E E(\%)=\left(1-\frac{\text { cargo amount detected in filtrate }}{\text { Theoretical cargo amount }- \text { cargo loss in tips }}\right) \times 100 \%
$$

RhoB and CN03 concentrations were quantified by measuring absorbance at $550 \mathrm{~nm}$ and at $254 \mathrm{~nm}$ using a UV-spectrophotometer (Biomolecular device) and a high-pressure liquid chromatography (HPLC) system (Dionex Ultimate 3000, ThermoFisher, Gothenburg, Sweden), respectively. For HPLC, mobile phases A and B were $5 \mathrm{mM}$ ammonium acetate buffer, and acetonitrile, respectively. Five microliters of the sample was injected into the column (Waters ${ }^{\circledR}$ XBridge C18 XP column, $50 \times 3 \mathrm{~mm}$ ). The HPLC quantification was performed using the Chromeleon software (v7.2, ThermoFisher, Gothenburg, Sweden) by calculating the peak area at the retention time of around $3.1 \mathrm{~min}$. The experiment was replicated 3 times for both UV-spectroscopy and HPLC.

\subsubsection{Stability Study}

Colloidal stability was assessed by monitoring the changes in size of the resulting nanoparticles over time. Concentrated SLN solution was diluted in $10 \mathrm{mM}$ PBS to reach $200 \mu \mathrm{g} / \mathrm{mL}$ concentration and stored in glass vials at either $25^{\circ} \mathrm{C}$ or $4{ }^{\circ} \mathrm{C}$ for a period of 
4 weeks. At each time point, the vials were gently shaken by hand and brought to room temperature prior to dynamic laser scattering analysis.

\subsection{Cell Culture}

The cells primarily affected in retinal degeneration are RPE and photoreceptors. For this study we chose two retinal cell types: (i) ARPE-19, a spontaneously arising human RPE cell line with normal karyotype [23]; (ii) 661W photoreceptor-like cells, derived from a mouse retinal tumor generated in a transgenic mouse expressing the SV40 large T-antigen under the control of the IRBP (interphotoreceptor retinoid-binding protein) promoter [24]. ARPE-19 cells were cultured in DMEM/F12 supplemented with 10\% FBS and 1\% penicillinstreptomycin in an incubator at $5 \% \mathrm{CO}_{2}$ and $37^{\circ} \mathrm{C}$. The murine photoreceptor $661 \mathrm{~W}$ cell line was cultured in low-glucose $(1 \mathrm{mg} / \mathrm{mL})$ DMEM supplemented with $10 \%$ FBS, $2 \mathrm{mM}$ glutamine, and $1 \%$ penicillin-streptomycin in an incubator at $5 \% \mathrm{CO}_{2}$ and $37{ }^{\circ} \mathrm{C}$. Approximately every three days, cells reached $70-80 \%$ confluence and were sub-cultured.

\subsection{Fluorescence Microscopic Analysis and Immunofluorescence}

Cells were seeded on glass coverslips in a 24-well plate at a density of $4 \times 10^{4}$ cells/well. After $24 \mathrm{~h}$, cells were exposed to RhoB-loaded SLN (RhoB-SLN). As control, cells were treated with free RhoB solution at the same concentration $(20 \mu \mathrm{M})$ as RhoB present in the nanoparticle solution. A blank was prepared by incubating the cells with nanoparticles containing no fluorophore.

For compound release assays, $24 \mathrm{~h}$ after seeding, ARPE-19 cells were treated with medium containing $200 \mu \mathrm{g} / \mathrm{mL}$ blank SLN (blank); freely dissolved tracer (ANTS); free tracer together with quencher (free ANTS/DPX), or $200 \mu \mathrm{g} / \mathrm{mL}$ SLN loaded with ANTS/DPX (ANTS/DPX-SLN). After $5 \mathrm{~h}$, the medium was replaced with fresh medium without any particles or fluorophores and the incubation was continued for $24 \mathrm{~h}, 48 \mathrm{~h}$, or $72 \mathrm{~h}$.

After incubation, cells were rinsed with phosphate-buffered saline (PBS), fixed with $2 \%$ PFA for $10 \mathrm{~min}$, and nuclei were stained with $0.1 \mu \mathrm{g} / \mathrm{mL}$ DAPI. For immunofluorescence, cells were incubated with anti-ZO-1 (1:100) primary antibody overnight at $4{ }^{\circ} \mathrm{C}$. After three washes with PBS, cells were incubated with Alexa Fluor ${ }^{\circledR} 488$ goat anti-rabbit secondary antibody (1:1000) and $0.1 \mu \mathrm{g} / \mathrm{mL}$ DAPI for $40 \mathrm{~min}$ at room temperature. Slides were mounted with Mowiol 4-88 and cells were observed using the Zeiss Axio Imager A2 fluorescence microscope. Mean fluorescence intensity (MFI) of single cells was quantified by ImageJ software ( $\left.\mathrm{n}_{\text {cells }} \geq 10\right)$.

\subsection{Cell Viability Assay}

Cell viability assay was performed by the colorimetric methyl-thiazolyl diphenyltetrazolium bromide (MTT) assay previously published for 661W cells [25]. Cells were seeded on 96-well plates at a density of 6000 cells/well. After treatment with SLN for various times, the medium was aspirated and cells were incubated with $50 \mu \mathrm{L}$ of $1 \mathrm{mg} / \mathrm{mL}$ MTT solution for $90 \mathrm{~min}$ at $37^{\circ} \mathrm{C}$. The supernatant was removed, and the purple formazan crystals were dissolved in $100 \mu \mathrm{L}$ isopropanol. The plate was shaken for $10 \mathrm{~min}$ and analyzed at $570 \mathrm{~nm}$ using a microplate reader (Labsystems Multiskan MCC/340, Fisher Scientific, Rodano, Italy).

\subsection{Flow Cytometry Analysis}

ARPE-19 and $661 \mathrm{~W}$ cells were seeded on 12 -well plates at a density of $1 \times 10^{5}$ cells/well. After treatment with control or SLN, cells were detached with $500 \mu \mathrm{L}$ Accutase ${ }^{\circledR}$ and collected by centrifugation at $300 \times g$ for $5 \mathrm{~min}$ at room temperature. The cells were washed three times with $500 \mu \mathrm{L}$ PBS and collected by centrifugation at $300 \times g$ for $5 \mathrm{~min}$ at room temperature. The cell pellet was resuspended with $500 \mu \mathrm{L}$ of PBS and RhoB fluorescence was immediately analyzed using an Attune ${ }^{\circledR}$ NxT Acoustic Focusing Cytometer (ThermoFisher, Rodano, Italy). The channel voltage and gain were maintained constant throughout the whole analysis. 


\subsection{Statistical Analysis}

Data are presented as the means \pm SEM (standard error of the mean). Student's $t$-test was applied to compare two groups. Analysis of variance (ANOVA) was used for comparisons of data with greater than two groups. Post hoc comparisons were performed with Bonferroni test. Significance was set at $p<0.05$, ${ }^{* *} p<0.01$, and ${ }^{* * *} p<0.001$. All statistical analyses were performed using SPSS (Statistics 21; IBM Inc., Bentoville, AR, USA). Data for each statistical analysis were obtained from at least three independent experiments, or three biological replicates for studies on cells.

\section{Results}

\subsection{Generation and Characterization of Solid Lipid Nanoparticles Containing a Gel Core}

The aim of this study was to develop a drug delivery system (DDS) to facilitate uptake of hydrophilic molecules by retinal cells. Among common thermoresponsive gels, such as poloxamer 407, chitosan, and hydroxypropyl methylcellulose (HPMG), which have been previously studied [19], we chose poloxamer 407 as the gel core material, because gelling can be easily induced by increasing temperature. For the lipidic shell, we used a mixture of lecithin (LCT), tripalmitin (GTP), and stearic acid (SA), since this mixture has been previously reported to be able to significantly enhance nanoparticle cellular uptake [26]. In addition, we added hydrophobic polyester to the lipid mixture to create a composite shell using biocompatible PCL and PLGA (Figure 1B). To evaluate encapsulation and cellular uptake, we chose rhodamine B (RhoB; $479.02 \mathrm{~g} / \mathrm{mol}$ ) as a small hydrophilic cargo that can be easily tracked during experiments. The summary of the generated SLN components is reported in Table S1.

The addition of hydrophobic polyesters, such as PCL and PLGA, may improve the particle polydispersity index (PDI) to less than 0.4 when used in combination with a gel core. Moreover, all of the produced nanoparticles were anionic, as characterized by their zeta potential. The addition of the gel core did not significantly affect the surface charge, e.g., SLN.03 $(-27 \pm 2.3 \mathrm{mV})$ versus SLN.06 $(-24 \pm 1.5 \mathrm{mV})$. On the other hand, the presence of the gel core improved the encapsulation efficiency, e.g., SLN.02 (24 $\pm 0.8 \%)$ versus SLN.05 $(48 \pm 0.44 \%)$. Both types of particles with a gel core could encapsulate above $40 \%$ RhoB, while particles with an aqueous core had RhoB encapsulation efficiency at around $20 \%$, regardless of the shell type. The addition of hydrophobic polyester to the shell formulation had no detectable effect on the encapsulation efficiency (Figure 2A). The SLN morphology, observed using TEM, confirmed that all the produced particles were smaller than $500 \mathrm{~nm}$, fulfilling the basic size requirement for mobility in the vitreous (Figure 2B).

Based on the analytical analyses of the generated SLN, we chose to focus on SLN.05 and SLN.06 for further studies, since they showed an improvement in PDI and encapsulation efficiency compared to conventional SLN with pure a lipid shell and no gel core (SLN.01). We first validated the formulation for encapsulation capability of SLN.05 and SLN.06 using a known compound previously shown to have neuroprotective properties in the retina, a compound called CN03 [27]. Both SLNs were able to encapsulate CN03 and resulted in negatively charged particles of $200-250 \mathrm{~nm}$. We noticed a higher encapsulation efficiency (i.e., $\pm 15 \%$ increase) compared to RhoB when $\mathrm{CN} 03$ was used (Figure $2 \mathrm{~A}$ ). A colloidal stability study was then performed with CNO3-loaded SLN dispersed in a PBS solution. The samples were stored at different storage temperatures for 4 weeks. An increase in size $( \pm 30 \mathrm{~nm})$ was observed in the SLN.05 colloidal solution after one week of storage (data not shown). In comparison, the SLN.06 colloidal solution showed better size stability within the study period. More importantly, the particle size was maintained below $300 \mathrm{~nm}$, regardless of storage temperature, within 1 month of storage (Figure 3). 


\section{A Physicochemical Characteristics}
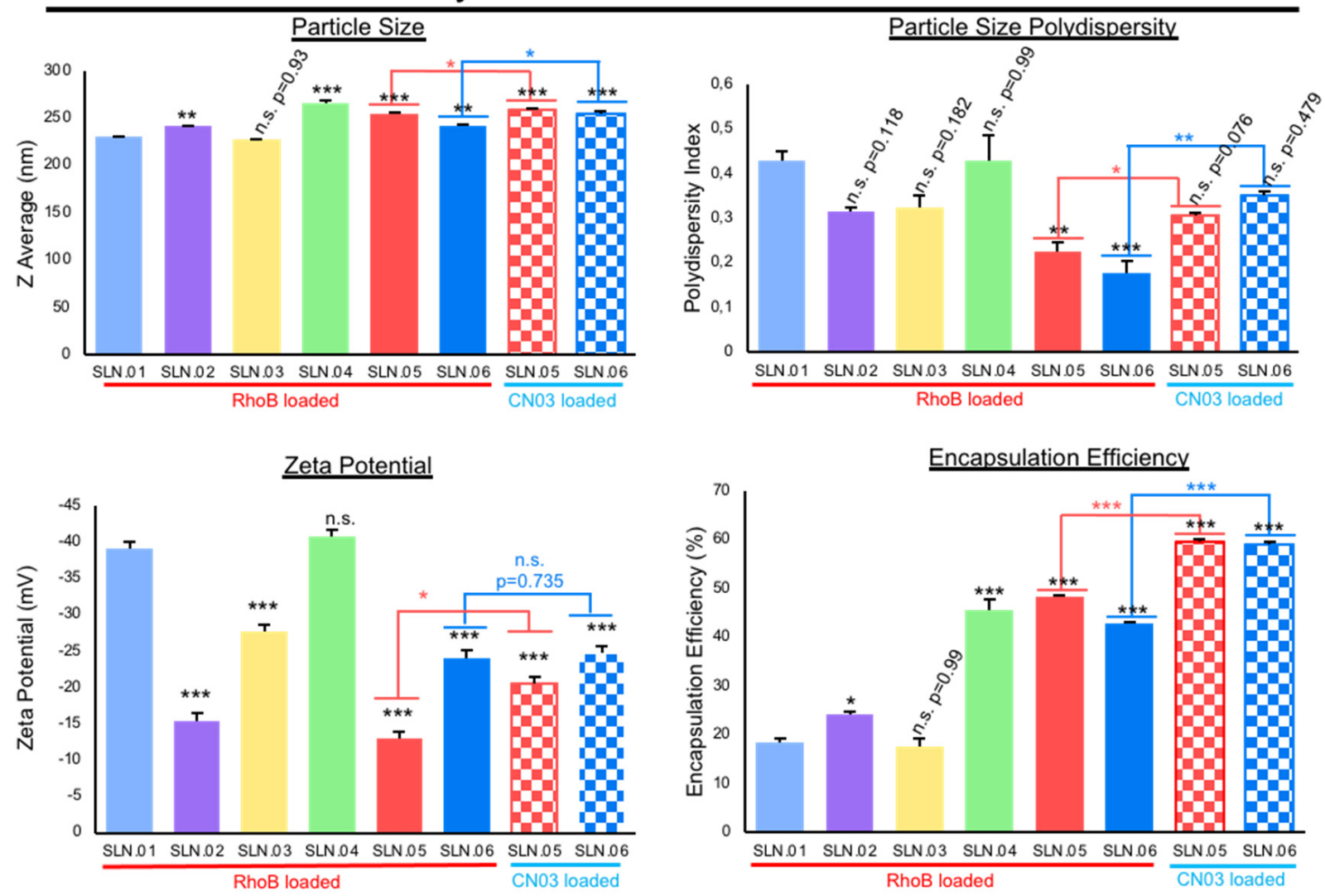

B

Morphological Characterization (TEM)

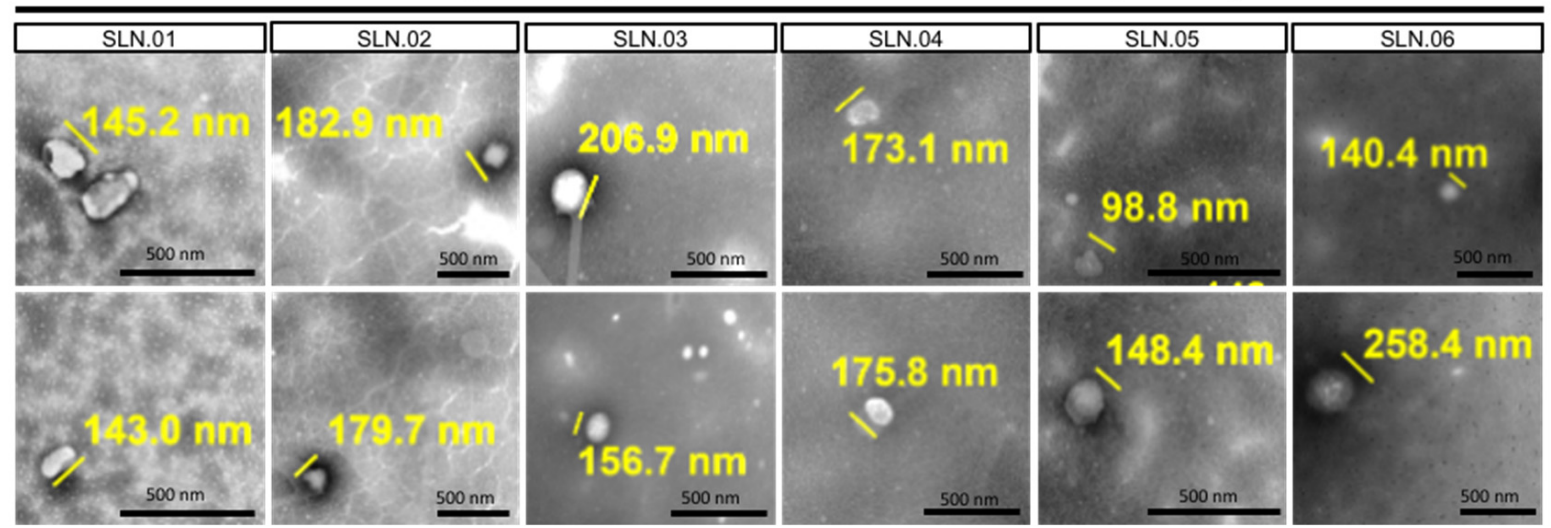

Figure 2. Characterization of SLNs. (A) Physicochemical characteristics of the generated SLN compared to conventional SLN (SLN.01). Data are presented as mean \pm SEM (standard error of the mean), $n=3$ independent experiments. Significance at ${ }^{*} p<0.05,{ }^{* *} p<0.01$, and ${ }^{* * *} p<0.001$; ANOVA followed by Bonferroni's post hoc test. Statistical analyses comparing SLN.05 and SLN.06 loaded with either RhoB or CN.03 were performed using Student's $t$-test. (B) Representative images of morphological analysis of blank SLNs without cargo using TEM. Scale bar: $500 \mathrm{~nm}$. 
SLN.05
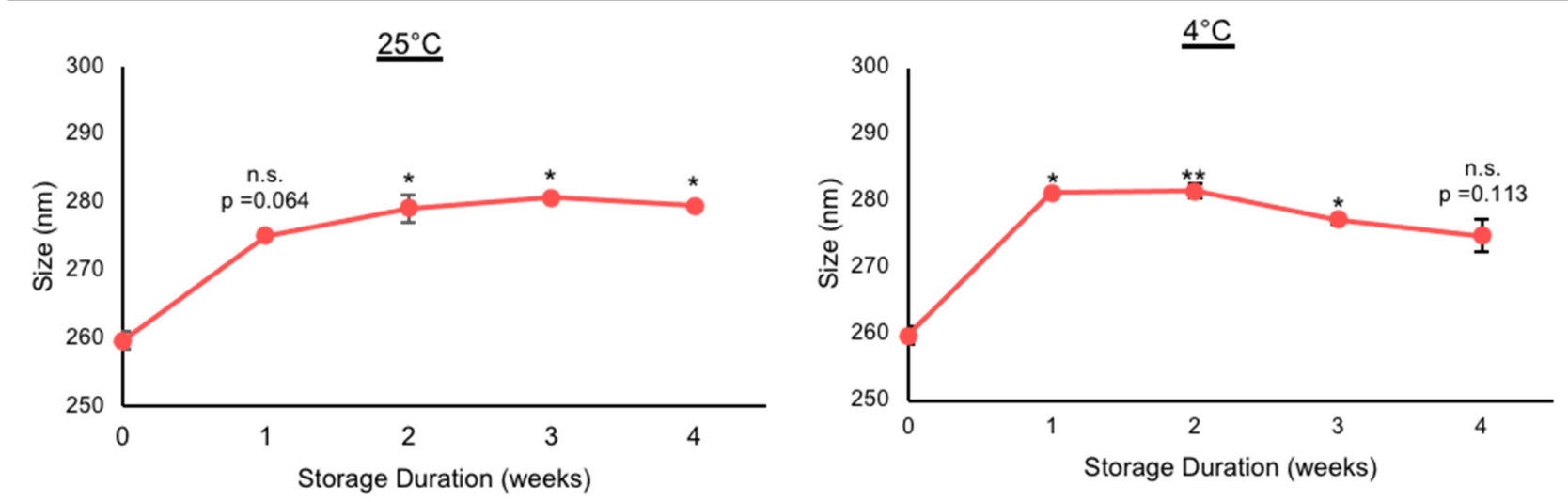

\section{SLN.06}
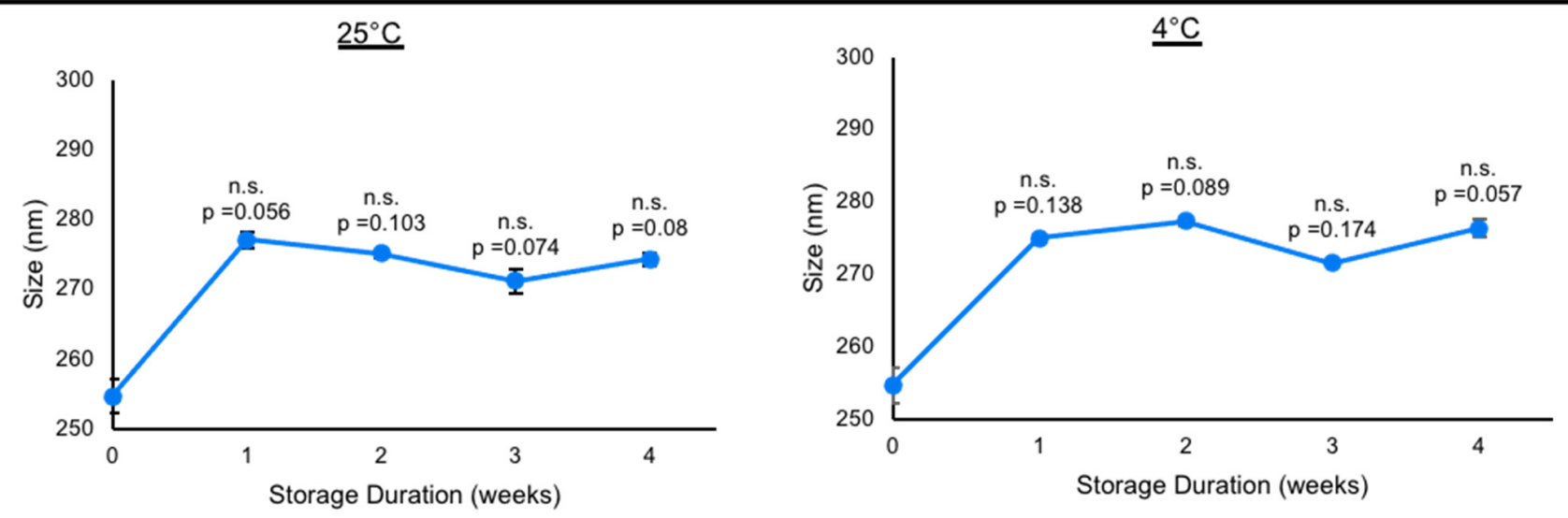

Figure 3. Stability study of nanoparticles containing CN03 in $10 \mathrm{mM}$ PBS at different storage temperatures. Stability of SLN.05 and SLN.06 stored in PBS at $25{ }^{\circ} \mathrm{C}$ and $4{ }^{\circ} \mathrm{C}$ was evaluated by analyzing the particle sizes every week for up to 4 weeks. Data are presented as mean \pm SEM (standard error of the mean), $n=3$ independent experiments. Significance at ${ }^{*} p<0.05$ and ${ }^{* *} p<0.01$; ANOVA followed by Bonferroni's post hoc test.

Taken together, all physicochemical characterization data show that SLN.05 and SLN.06 have relatively good properties to be further in vitro validated as a potential DDS for retinal cells.

\subsection{Evaluation of SLN.05 and SLN.06 Toxicity to ARPE-19 and 661W Retinal Cell Lines}

We used ARPE-19 cells (human retinal pigment epithelium cell line) and 661W cells (mouse photoreceptor-like cell line) to evaluate the toxicity of SLNs on retinal cells. We exposed ARPE-19 and 661W cells to either SLN.05 or SLN.06 at different concentrations and evaluated toxicity by the MTT cell viability assay at different time points.

Both SLN.05 and SLN.06 showed increased toxicity in a dose-dependent manner and a time-dependent manner (Figure 4A,B). Overall, SLN.05 showed higher toxicity in both cell types. Toxicity of SLN.05 to ARPE-19 cells started to be detected at $200 \mu \mathrm{g} / \mathrm{mL}$ after $5 \mathrm{~h}$ of exposure. Interestingly, $661 \mathrm{~W}$ cells showed higher resistance to SLN.05 toxicity, because $200 \mu \mathrm{g} / \mathrm{mL}$ of SLN.05 did not significantly reduce $661 \mathrm{~W}$ viability even after exposure for $24 \mathrm{~h}$, but started to be toxic at $500 \mu \mathrm{g} / \mathrm{mL}$. SLN. 06 was less toxic to both cell lines, especially to $661 \mathrm{~W}$ cells. ARPE-19 cells could tolerate up to $500 \mu \mathrm{g} / \mathrm{mL}$ of SLN.06 within $5 \mathrm{~h}$ of exposure, while $661 \mathrm{~W}$ cells could tolerate up to $800 \mu \mathrm{g} / \mathrm{mL}$ of SLN. 06 within $24 \mathrm{~h}$ exposure. SLNs reduced viability of both ARPE-19 and $661 \mathrm{~W}$ cells after $48 \mathrm{~h}$ of exposure. 
A ARPE-19 Cell
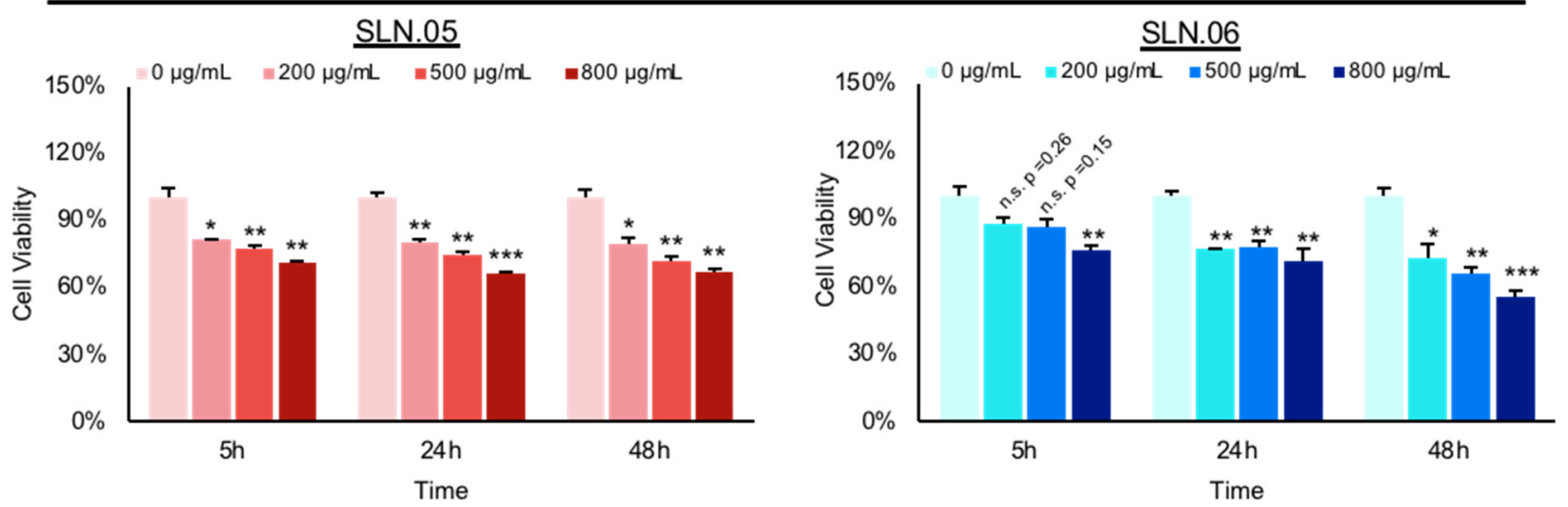

$\mathrm{B}$

661W Cell
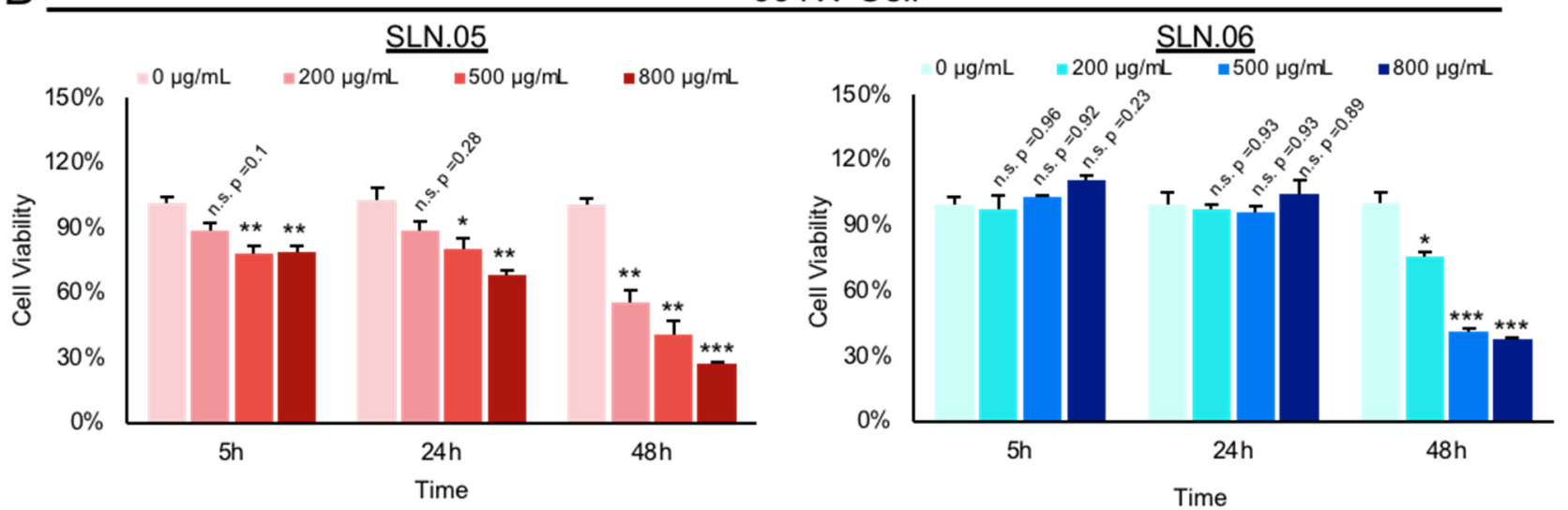

Figure 4. Toxicity of SLN to ARPE-19 and 661W retinal cell lines. Toxicity of SLN.05 and SLN.06 to retinal cell lines was assessed by measuring the percentage of cell viability after exposure of SLN at various concentrations and at different time points using MTT assay. Untreated cells $(0 \mu \mathrm{g} / \mathrm{mL})$ were set as $100 \%$ cell viability and used as a control. (A) Percentage viability of ARPE-19 cells after exposure to SLN.05 or SLN.06. (B) Percentage of 661W cells viability after exposure to SLN.05 or SLN.06. Data are presented as mean \pm SEM (standard error of the mean), $n=3$ independent experiments. Significance at ${ }^{*} p<0.05,{ }^{* *} p<0.01,{ }^{* * *} p<0.001$; ANOVA followed by Bonferroni's post hoc test.

\subsection{SLN.05 and SLN.06 Internalization by Retinal Cell Lines}

To deliver small hydrophilic molecules to retinal cells, SLNs need to be efficiently internalized by cells. To visualize SLN uptake, we used RhoB-loaded SLNs (RhoB-SLN). Both RhoB-SLN.05 and RhoB-SLN.06 could be efficiently internalized by $661 \mathrm{~W}$ cells, where RhoB intensity in the cytosol increased in a concentration-dependent manner (Figure 5A,B). To further confirm and quantify internalization efficiency of SLNs, we exposed 661W cells to $200 \mu \mathrm{g} / \mathrm{mL}$ of RhoB-SLN.05 and RhoB-SLN.06 and quantified the fluorescence signal at different time points by flow cytometry. Since free RhoB can also penetrate the cells, we used cells treated with free RhoB suspension for $5 \mathrm{~h}$ as the control. Only $0.08 \%$ of $661 \mathrm{~W}$ cells were positive for RhoB after treatment with free RhoB for $5 \mathrm{~h}$, indicating that RhoB diffusion inside the cells was very low. One hour exposure to RhoB-loaded SLN was sufficient to detect $3.28 \%$ of RhoB-positive $661 \mathrm{~W}$ cells after incubation with RhoB-SLN.05 and 3.35\% of positive $661 \mathrm{~W}$ cells after incubation with RhoB-SLN.06. The percentage of RhoB-positive cells increased with longer incubation time (Figure 5C). Similarly, we observed the same trend in SLN uptake by ARPE-19 cells (Figure S1). Taken together, these data indicate that SLN.05 and SLN.06 can be internalized by both photoreceptor and RPE cell types. 
A

RhodamineB/DAPI

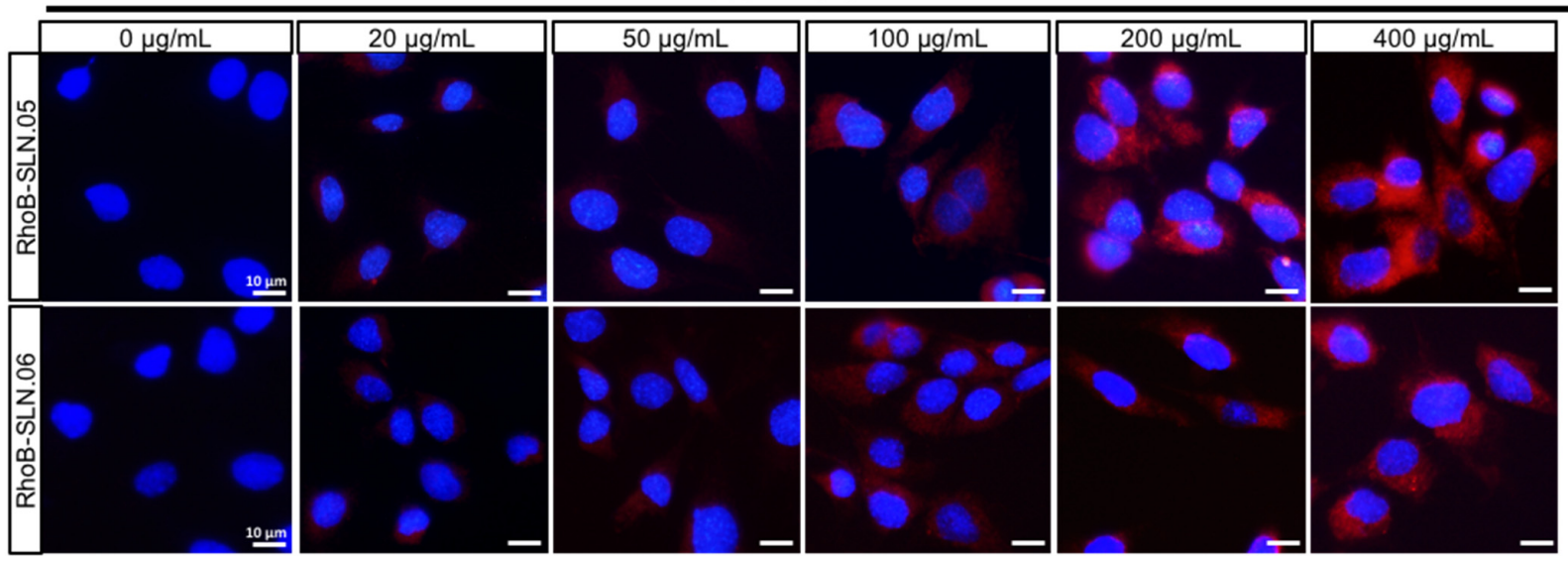

B
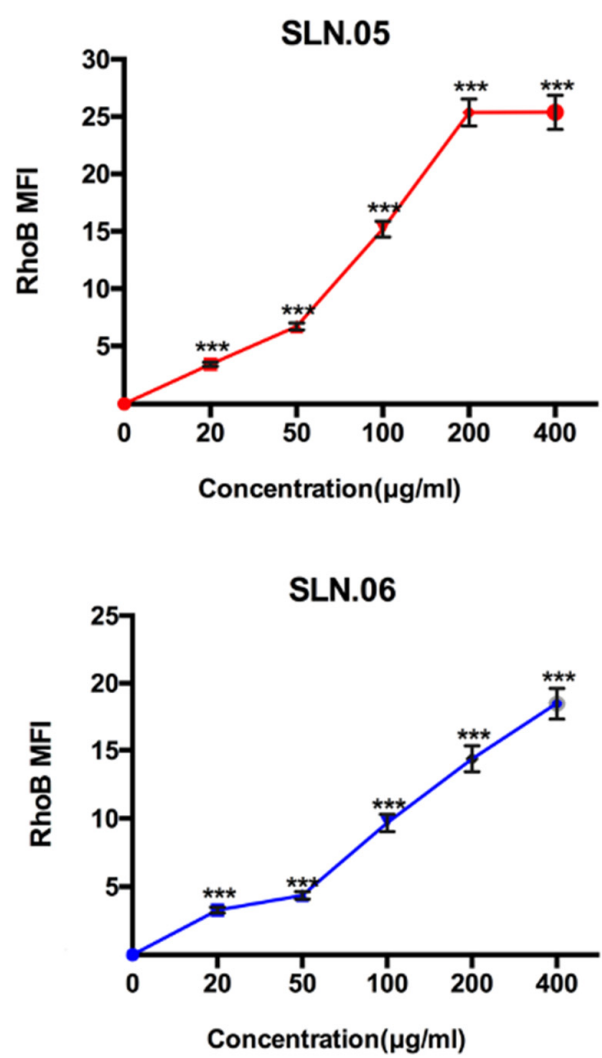

C

Untreated 661W

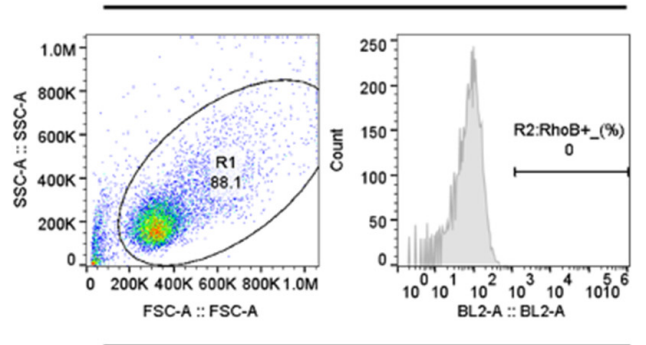

Treated 661W

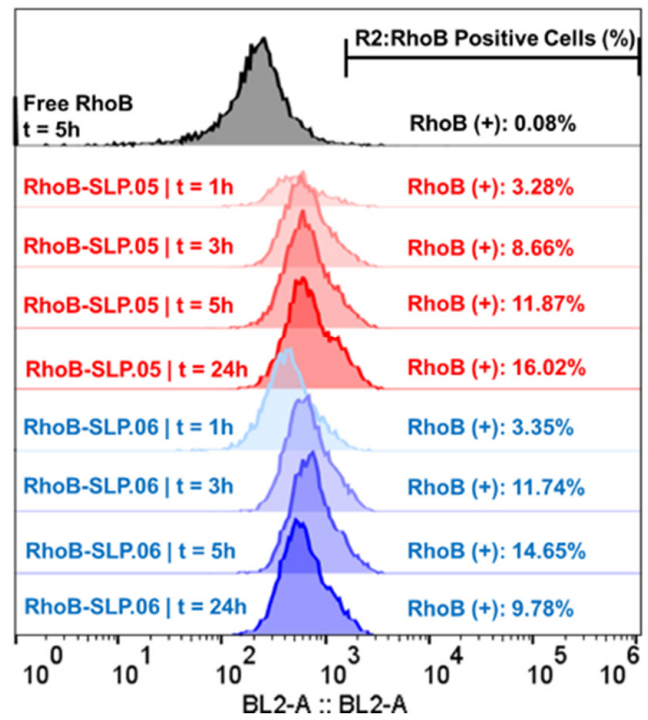

Figure 5. Internalization of SLN.05 or SLN.06 by 661W cells. (A) Visualization of internalized SLN by $661 W$ cells using rhodamine B-loaded SLN (RhoB-SLN). Micrographs of internalized RhoB-SLN.05 or RhoB-SLN.06 (red signal) at various concentrations after $5 \mathrm{~h}$ of exposure. Nuclei were stained with DAPI in blue. Scale bar: $10 \mu \mathrm{m}$. (B) Mean fluorescence intensity (MFI) of rhodamine B signal inside the cells was quantified using the ImageJ software $\left(\mathrm{n}_{\text {cells }} \geq 10\right)$. (C) Histogram overlay of RhoB relative fluorescence intensity and percentage of RhoB-positive cells (RhoB+) assessed by Flow cytometry. R1: gating for selecting cell population; R2: gating to select RhoB+ cells based on blue laser (BL2-A) detector; FSC-A: forward scattering channel; SSC-A: side scattering channel. Significance at *** $p<0.001$; ANOVA followed by Bonferroni's post hoc test. 
We visually confirmed the intracellular localization of SLNs after being internalized by the ARPE-19 cells by staining the membrane of the cells with an anti-ZO-1 antibody (specific antibody that recognize a peripheral membrane protein in epithelial cells), and we observed that RhoB-SLNs are localized inside the cytosol after the internalization process (Figure 6A). To elucidate the mechanism of the internalization of SLN.05 and SLN.06 by the photoreceptor cells, we exposed $661 \mathrm{~W}$ cells to $200 \mu \mathrm{g} / \mathrm{mL}$ of RhoB-SLN.05 and RhoBSLN.06 for $1 \mathrm{~h}$ at either $37^{\circ} \mathrm{C}$ or $4{ }^{\circ} \mathrm{C}$. We observed that incubation at $4{ }^{\circ} \mathrm{C}$ highly limited the uptake of Rho-SLNs, indicating an energy-dependent process rather than passive membrane passage (Figure 6B). Based on the knowledge that most of the nanoparticles are internalized by cells through endocytosis [28], these data confirmed that SLN.05 and SLN.06 were taken up via an endocytic process rather than membrane permeation.

\subsection{Encapsulated Cargo Release Inside the Cells}

To evaluate if SLN.05 and SLN.06 can successfully release the cargo after being uptaken by the cells, we performed a fluorescence leakage assay using ANTS/DPX, which has been widely used to study vesicle leakage [29]. We encapsulated the ANTS fluorescent dye together with its quencher DPX. Once the SLN shell breaks and releases the cargo inside the cells, DPX will no longer be able to quench ANTS due to the increase of the molecular distance between ANTS and DPX, which allows free ANTS inside the cells to emit green fluorescence (Figure 7A). In this experiment, we exposed cells to either free ANTS or DPX, which are not able to penetrate the cells, as controls. Only cells exposed to SLN.05 and SLN.06 loaded with ANTS/DPX resulted in fluorescence, demonstrating that SLNs could successfully deliver ANTS/DPX inside the cells and release the cargo (Figure 7B,C). A faint signal could be detected at $24 \mathrm{~h}$, but a full signal was easily detected after $48 \mathrm{~h}$ of exposure (Figure 7C). Taken together, these data demonstrate that the new formulated SLNs are able to release a hydrophilic molecule inside a retinal cell and can be an efficient drug delivery system for the retina. 
A

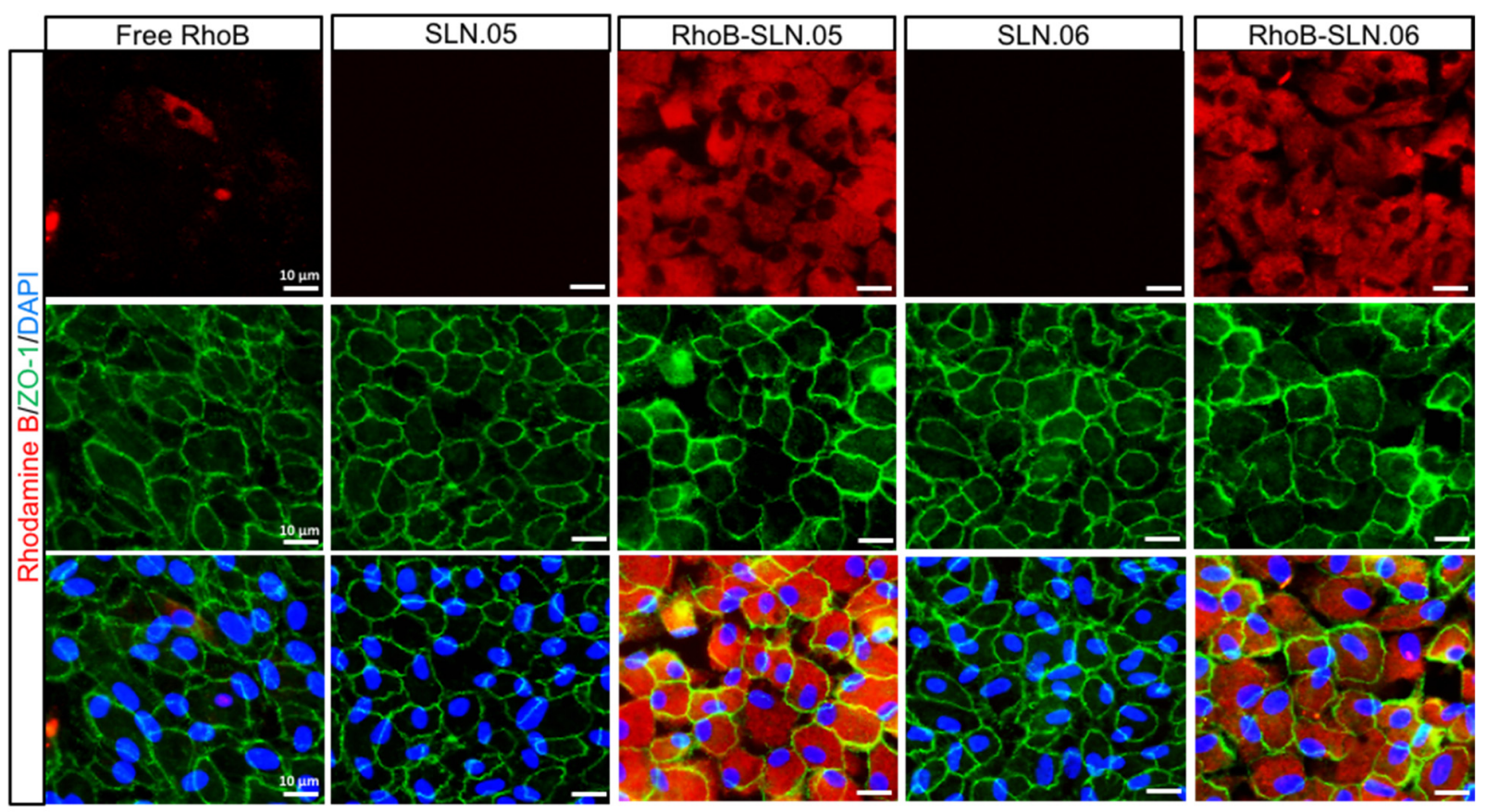

B
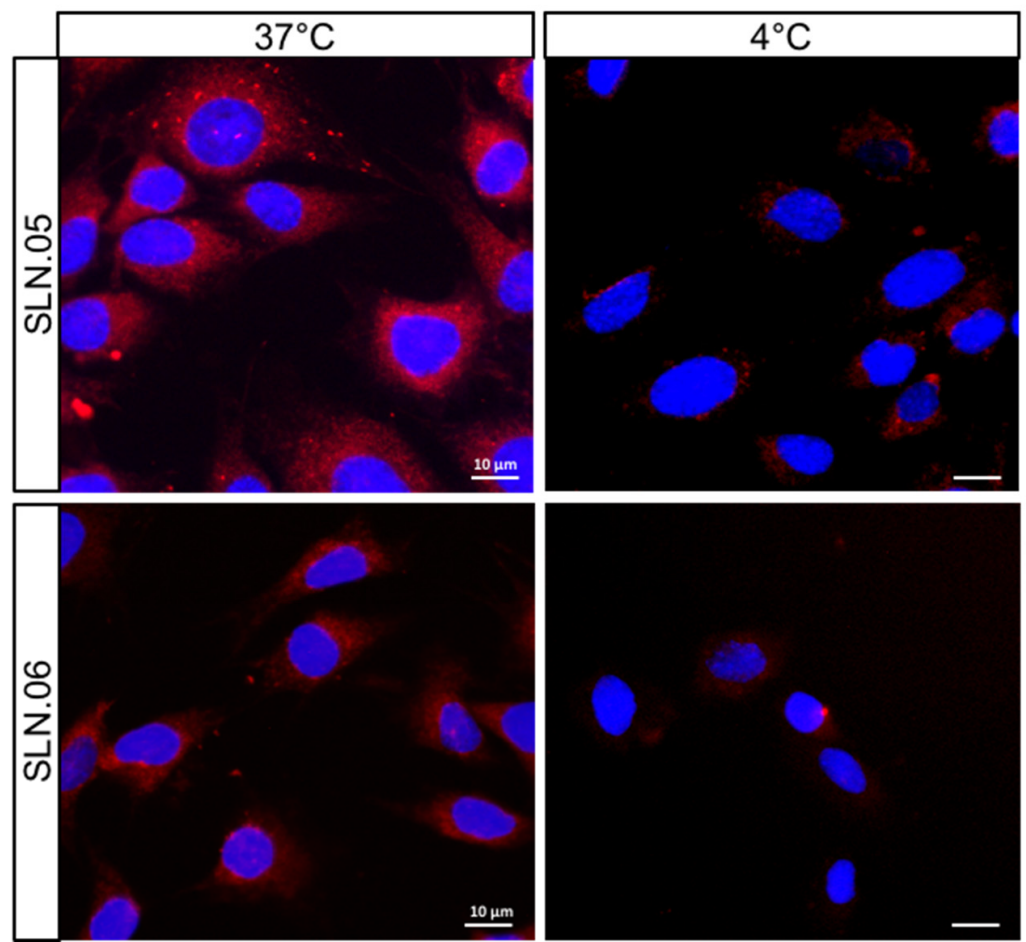

Figure 6. Internalization of SLN.05 or SLN.06 by ARPE-19 cells. (A) Micrographs showing intracellular localization of RhoB-SLN.05 or RhoB-SLN.06 (red signal) in ARPE-19 cells. Cell membranes were stained with anti-ZO-1 antibody (green). Nuclei of cells were stained with DAPI (blue). Scale bar: $10 \mu \mathrm{m}$. (B) Representative images showing temperature-dependent RhoB-SLN.05 or RhoB-SLN.06 (red signal) uptake by $661 \mathrm{~W}$ cells at either $37^{\circ} \mathrm{C}$ or $4^{\circ} \mathrm{C}$. Nuclei of cells were stained with DAPI in blue. Scale bar: $10 \mu \mathrm{m}$. 

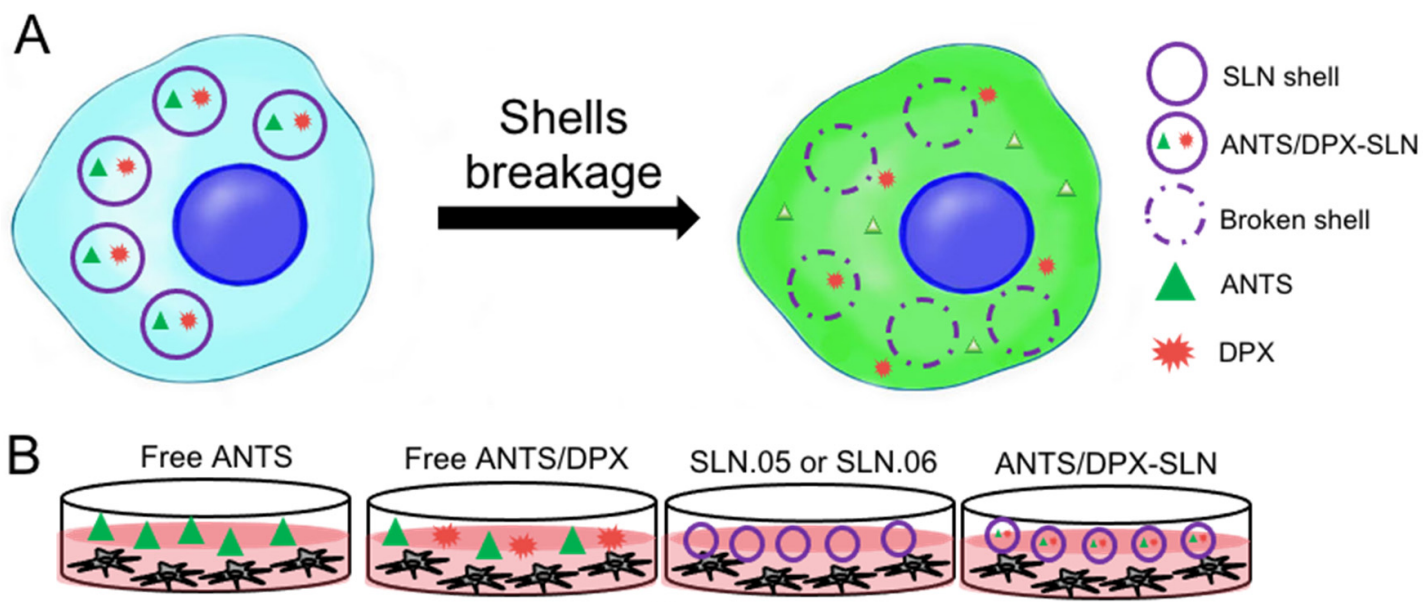

Treatment for 5 hours, followed by washing and changing with fresh medium

Analysis at $24 \mathrm{~h}, 28 \mathrm{~h}$, and $72 \mathrm{~h}$

$\mathrm{C}$

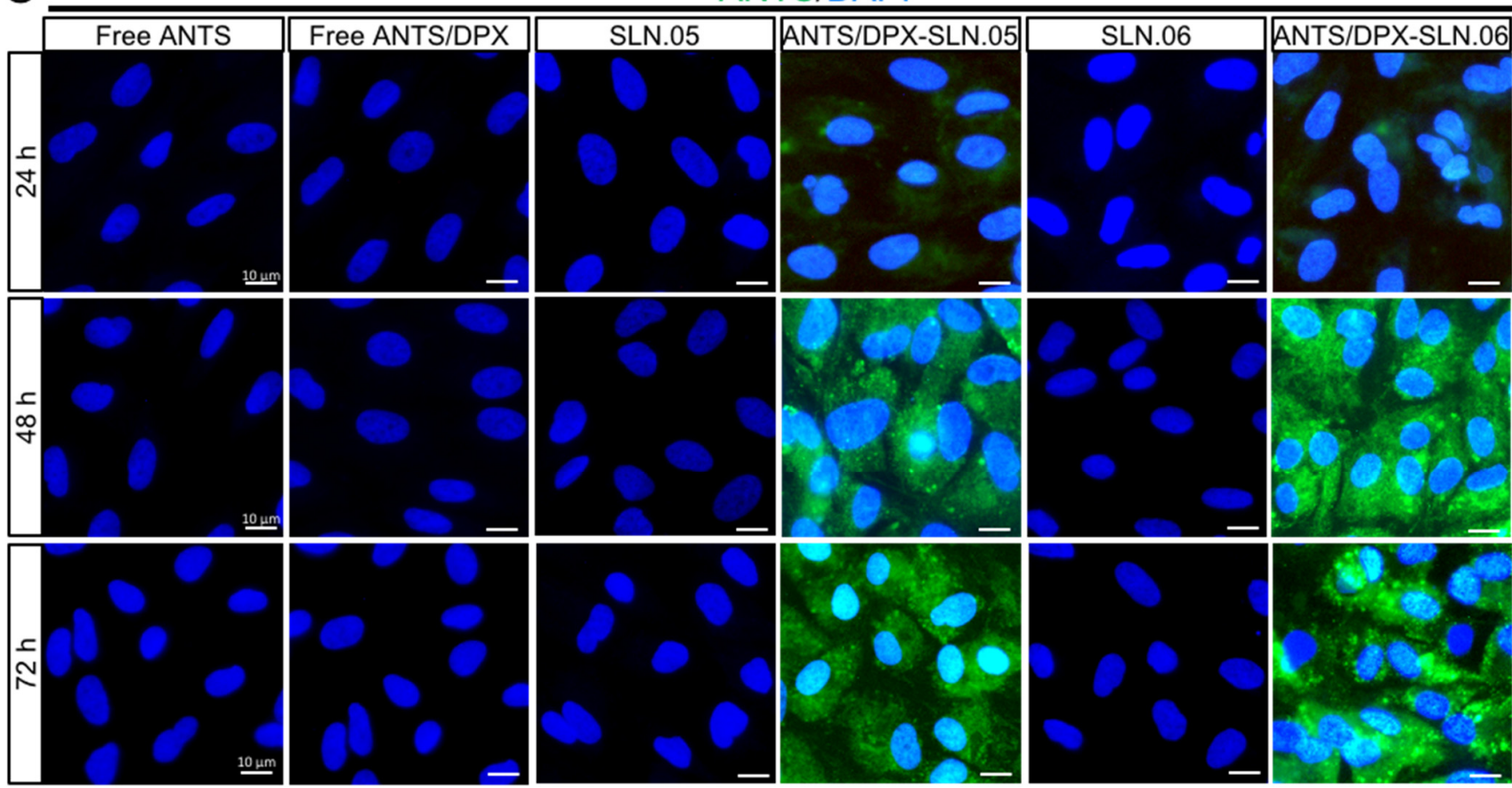

Figure 7. SLN.05 or SLN.06 cargo release inside the cells. Fluorescence leakage assay using ANTS/DPX was used to determine cargo delivery and release by the SLN.05 or SLN.06 inside the cells. (A) Schematic summary of fluorescence leakage assay using ANTS/DPX. (B) Schematic of experimental design for fluorescence leakage assay. (C) Micrographs of ARPE-19 cells exposed to ANTS/DPX-loaded SLN.05 and SLN.06. Released ANTS (green) was detectable only in cells exposed to ANTS/DPX loaded into SLNs, and not in cells exposed to free ANTS and/or DPX. Nuclei of cells were stained with DAPI in blue. Scale bar: $10 \mu \mathrm{m}$.

\section{Discussion}

The delivery of a drug to the neural retina is challenging due to the different barriers that need to be crossed and the physicochemical environment of the vitreous that may affect the passage of the drug to the target cells. In this study we presented new formulations of nanoparticles that could enter retinal cells while having features that may facilitate 
navigation across the vitreous (e.g., size $<500 \mathrm{~nm}$ and anionic). The key findings from the formulation development studies were: (i) the gel core improved the encapsulation efficiency by up to 2-fold; (ii) the addition of hydrophobic polymer to the shell could be used to tailor the surface charge of the final DDS. Our encapsulation efficiency results suggested that the gel core could improve the small hydrophilic cargo retention during formulation. This agreed with previous reports that used large macromolecules as cargo [19]. Most likely, the improved retention came from the solidification of Poloxamer 407 emulsion droplets. Poloxamer 407 droplets formed a nanogel thanks to a local increase in temperature during the sonication process. Particle surface charge should be considered in terms of cellular uptake. The cellular membrane is generally negatively charged and thus, a strongly anionic particle will have more difficulty to enter the cells compared with a cationic particle [30]. However, when the particle is cationic, it will have a tendency to aggregate in the vitreous [11]. Thus, there is a need to tailor particle surface charge during DDS development. The addition of polyester to the shell formulation reduced the strong negative charge of the pure lipid SLN shell (SLN.01; $-39 \mathrm{mV}$ ). The intensity of the surface charge reduction differed based on the hydrophobic polymer used as a filler in the composite SLN shell formulation (i.e., PCL and PLGA were used in this study). Particle shells containing PCL (SLN.02; $-15 \mathrm{mV}$ ) had a higher zeta potential reduction compared to PLGA (SLN.03; $-27 \mathrm{mV}$ ). The charge reduction, observed from adding PCL or PLGA to create a composite shell, may indicate that the hydrophobic polymeric chains are well distributed on the surface. The intensity of surface charge observed is very likely related to the inherent surface charge of the polymer used. Based on this finding, the choice of hydrophobic polymeric components in the composite SLN shell may be used to tailor specific surface charges in further stages of DDS development.

The SLN formulation initially developed with RhoB, as the hydrophilic cargo, was validated with a real drug for retinal degeneration (i.e., CN03). The freshly synthesized CN03-loaded SLN particle size was maintained in the range of 200-250 nm. There was a significant change in surface charge when CN03 salts were used instead of RhoB for SLN.05. However, this was not observed in SLN.06. Without CN03 salts, SLN.05 (-13 mV) had a less negative charge than SLN.06 $(-24 \mathrm{mV})$. Thus, unencapsulated CN03 salts had a weaker influence or had less surface absorption on a more negatively charged SLN. We also observed an increase in polydispersity when CN03 salts were used as the cargo. Colloidal system is a delicate particulate system, which is strongly influenced by the salts and $\mathrm{pH}$ from the dispersing medium. The increase in polydispersity may come from the effect of unencapsulated CN03 salts during the synthesis. Finally, there was an increase of about $15 \%$ in encapsulation efficiency of CN03 compared to RhoB. This may be due to the fact that CN03, which is in a sodium salt form, has a much lower solubility in dichloromethane compared to RhoB. Thus, RhoB, can possibly leak out from the $\mathrm{W}_{1}$ phase during the DDS preparation compared to CN03. Based on this finding, we surmise that this DDS may also work for other hydrophilic cargos with lower solubility in the organic solvent (e.g., DNA) for different pharmaceutical application.

The colloidal stability study, which was the last checkpoint in this work prior to in vitro studies, showed a $\pm 30 \mathrm{~nm}$ increase in particle size for SLN.05 after the first week of storage. The observed increase in particle size may be caused by the high concentration of salts from PBS, which disrupts the colloidal solution stability. However, SLN.06, which had a more negatively charged surface compared to SLN.05, showed a statistically better stability profile throughout the study. This observation might come from the fact that the magnitude of particle-to-particle repulsion, which could help prevent aggregation, is proportional to the intensity of the particle surface charge. While SLN.06 may seem to perform better than SLN.05 in terms of prolonged colloidal stability in salt solution, the size of both SLNs was maintained below $300 \mathrm{~nm}$ throughout the stability study regardless of the storage temperature and duration. Based on these characteristics, both SLN.05 and SLN.06 were selected for in vitro studies using 661W and ARPE-19 cells. 
While both SLN.05 and SLN.06 caused time- and dose-dependent toxicity in the cells, the in vitro cytotoxicity studies provided insight that the two retinal cell lines had different sensitivity to these SLNs. This agreed with previous studies reporting that distinctive cell physiology, proliferation rate, metabolic activity, membrane, and phagocytosis characteristics are responsible for the different sensitivity to external factors [30,31]. Physicochemical elements of nanoparticles can also affect the cytotoxicity of cells [30]. Specifically, distinct shell composition of SLN.05 and SLN.06 may differently affect viability of retinal cells. With regards to cytotoxicity, SLN.06 seemed to perform better than SLN.05 as a DDS.

Internalization studies in the two retinal cell types demonstrated that: (i) the SLN formulation helped the internalization of small hydrophilic compounds; (ii) the SLN shell component might be used to tailor the uptake rate in different cell types. We observed that ARPE-19 cells had better uptake of SLN containing PCL in the shell (SLN.05). This might be due to the fact that SLN.05 is less negatively charged compared to SLN.06 (Figure 2A) and the uptake level is directly affected by the physicochemical properties of SLN, such as shape, size, and surface charge [32]. In 661W cells, the uptake profile of SLN.06 nanoparticle was similar to that measured in APRE-19 cells and is limited to a low percentage of cells internalized by the nanoparticles. For SLN.05, lower uptake was observed in $661 \mathrm{~W}$ compared to ARPE-19. This difference may be attributed to the fact that uptake rates are also specific to each cell type [33]. It is not surprising that photoreceptor cells have a lower uptake rate compared to ARPE-19 cells, because RPE cells are characterized by a high rate of phagocytosis, which is one of their daily functions to remove the apical part of photoreceptor outer segments [34]. The reduced uptake at $4{ }^{\circ} \mathrm{C}$ suggested that the SLN mainly enter the cells via endocytosis, as energy-dependent endocytosis will be largely inhibited at this temperature [35-37]. We also demonstrated that SLN could release their cargo after being internalized by the cells. This result highlights that the newly developed DDS was appropriate for the encapsulation of small hydrophilic drugs and for their release into the target cells.

Overall, both SLN.05 and SLN.06 could successfully improve the uptake of small hydrophilic cargos into retinal cell lines in vitro. SLN.06 seemed to perform better as a DDS when compared to SLN.05 considering its slight advantages in terms of stability and cytotoxicity. Finally, while the relatively simple cell culture environment yielded interesting data, full drug/DDS efficacy testing will likely require more complex test systems. More advanced in vitro tests using in vivo injections or organotypic retinal explant cultures, in which the normal histotypic context of the retina is preserved [38], will further characterize the suitability of the new SLN for delivery to the retina. The fate of SLN materials after being broken down inside the cells, and the specific mechanism on how they are metabolized, will be the focus of further research. Nevertheless, based on these developments and initial validation studies, our work may open new perspectives for developing a treatment for retinal diseases based on SNL with small hydrophilic cargos.

\section{Conclusions}

This study presents an SLN formulation capable of encapsulating a small hydrophilic cargo and delivering it to retinal cells in vitro. The study highlighted that a gel core could significantly increase the encapsulation efficiency of small hydrophilic cargo inside the SLN (i.e., up to $\pm 60 \%$ with a gel core compared to initial $\pm 20 \%$ with only an aqueous core). We also observed that the type of hydrophobic polymer used in the composite shell may affect the particle surface charge, a key factor for intravitreal drug delivery systems. The physicochemical properties of the DDS developed using RhoB were retained when the neuroprotective cGMP analog CN03 was used as a cargo. The SLN maintained its particle size below $300 \mathrm{~nm}$ after 1 month of storage in PBS. The in vitro study demonstrated that the DDS could be taken up by model retinal cell lines (i.e., ARPE-19 and 661W), with different uptake rates based on the particle shell composition and cell type. Equally importantly, the DDS could release its cargo inside the cells. While the current results are promising for an 
early-stage formulation development study, more complex in vivo studies are needed to demonstrate the clinical relevance of the newly developed DDS.

Supplementary Materials: The following are available online at https:/ / www.mdpi.com/article/ 10.3390 / pharmaceutics14010074/s1, Table S1. Formulation code and component mass dissolved in O-phase for each formulation, Figure S1. Flow cytometry analysis of ARPE-19 cells positive for RhoB after incubation with $200 \mu \mathrm{g} / \mathrm{mL}$ RhoB-SLN.05 or RhoB/SLN.06 at different time point.

Author Contributions: Conceptualization, L.H., E.H., M.B. and V.M.; Data curation, L.H. and E.H.; Funding acquisition, F.P.D., N.S. and V.M.; Methodology, L.H., S.B. and R.O.P.G.; Supervision, A.S. and V.M.; Writing —original draft, L.H. and E.H.; Writing—review \& editing, F.P.D., N.S. and V.M. All authors have read and agreed to the published version of the manuscript.

Funding: This study was supported by grants from the European Union (transMed; H2020-MSCAITN-765441) and the Charlotte and Tistou Kerstan Foundation.

Institutional Review Board Statement: Not applicable.

Informed Consent Statement: Not applicable.

Data Availability Statement: The raw data supporting the conclusions of this article will be made available upon request.

Acknowledgments: We thank Gareth R. Williams from University College London for his assistance in TEM images. We thank M. Montanari for technical support on flow cytometry.

Conflicts of Interest: E.H., M.B. and A.S. were employed by the company InoCure s.r.o. InoCure s.r.o had no role in the design of the study; in the collection, analyses, or interpretation of data; in the writing of the manuscript, or in the decision to publish the results. The remaining authors declare that the research was conducted in the absence of any commercial or financial relationships that could be construed as a potential conflict of interest.

\section{References}

1. Lechner, J.; O'Leary, O.E.; Stitt, A.W. The pathology associated with diabetic retinopathy. Vision Res. 2017, 139, 7-14. [CrossRef]

2. Mitchell, P.; Liew, G.; Gopinath, B.; Wong, T.Y. Age-related macular degeneration. Lancet 2018, 392, 1147-1159. [CrossRef]

3. Swaroop, A.; Sieving, P.A. The golden era of ocular disease gene discovery: Race to the finish. Clin. Genet. 2013, 84, 99-101. [CrossRef]

4. Chakravarthy, U.; Biundo, E.; Saka, R.O.; Fasser, C.; Bourne, R.; Little, J.A. The Economic Impact of Blindness in Europe. Ophthalmic Epidemiol. 2017, 24, 239-247. [CrossRef]

5. Gallego, I.; Villate-Beitia, I.; Martínez-Navarrete, G.; Menéndez, M.; López-Méndez, T.; Soto-Sánchez, C.; Zárate, J.; Puras, G.; Fernández, E.; Pedraz, J.L. Non-viral vectors based on cationic niosomes and minicircle DNA technology enhance gene delivery efficiency for biomedical applications in retinal disorders. Nanomed. Nanotechnol. Biol. Med. 2019, 17, 308-318. [CrossRef]

6. Tolone, A.; Belhadj, S.; Rentsch, A.; Schwede, F.; Paquet-Durand, F. The cGMP pathway and inherited photoreceptor degeneration: Targets, compounds, and biomarkers. Genes 2019, 10, 453. [CrossRef] [PubMed]

7. Li, Q.; Li, X.; Zhao, C. Strategies to Obtain Encapsulation and Controlled Release of Small Hydrophilic Molecules. Front. Bioeng. Biotechnol. 2020, 8, 437. [CrossRef] [PubMed]

8. Himawan, E.; Ekström, P.; Buzgo, M.; Gaillard, P.; Stefánsson, E.; Marigo, V.; Loftsson, T.; Paquet-Durand, F. Drug delivery to retinal photoreceptors. Drug Discov. Today 2019, 24, 1637-1643. [CrossRef]

9. Gorantla, S.; Rapalli, V.K.; Waghule, T.; Singh, P.P.; Dubey, S.K.; Saha, R.N.; Singhvi, G. Nanocarriers for ocular drug delivery: Current status and translational opportunity. RSC Adv. 2020, 10, 27835-27855. [CrossRef]

10. Peeters, L.; Sanders, N.N.; Braeckmans, K.; Boussery, K.; Van de Voorde, J.; De Smedt, S.C.; Demeester, J. Vitreous: A Barrier to Nonviral Ocular Gene Therapy. Investig. Opthalmol. Vis. Sci. 2005, 46, 3553. [CrossRef] [PubMed]

11. Xu, Q.; Boylan, N.J.; Suk, J.S.; Wang, Y.Y.; Nance, E.A.; Yang, J.C.; McDonnell, P.J.; Cone, R.A.; Duh, E.J.; Hanes, J. Nanoparticle diffusion in, and microrheology of, the bovine vitreous ex vivo. J. Control. Release 2013, 167, 76-84. [CrossRef]

12. Tavakoli, S.; Kari, O.K.; Turunen, T.; Lajunen, T.; Schmitt, M.; Lehtinen, J.; Tasaka, F.; Parkkila, P.; Ndika, J.; Viitala, T.; et al. Diffusion and Protein Corona Formation of Lipid-Based Nanoparticles in the Vitreous Humor: Profiling and Pharmacokinetic Considerations. Mol. Pharm. 2021, 18, 699-713. [CrossRef]

13. del Amo, E.M.; Rimpelä, A.K.; Heikkinen, E.; Kari, O.K.; Ramsay, E.; Lajunen, T.; Schmitt, M.; Pelkonen, L.; Bhattacharya, M.; Richardson, D.; et al. Pharmacokinetic aspects of retinal drug delivery. Prog. Retin. Eye Res. 2017, 57, 134-185. [CrossRef] [PubMed] 
14. Apaolaza, P.S.; del Pozo-Rodríguez, A.; Solinís, M.A.; Rodríguez, J.M.; Friedrich, U.; Torrecilla, J.; Weber, B.H.F.; RodríguezGascón, A. Structural recovery of the retina in a retinoschisin-deficient mouse after gene replacement therapy by solid lipid nanoparticles. Biomaterials 2016, 90, 40-49. [CrossRef] [PubMed]

15. Bisht, R.; Mandal, A.; Jaiswal, J.K.; Rupenthal, I.D. Nanocarrier mediated retinal drug delivery: Overcoming ocular barriers to treat posterior eye diseases. Wiley Interdiscip. Rev. Nanomed. Nanobiotechnol. 2018, 10, e1473. [CrossRef]

16. Zariwala, M.G.; Bendre, H.; Markiv, A.; Farnaud, S.; Renshaw, D.; Taylor, K.M.G.; Somavarapu, S. Hydrophobically modified chitosan nanoliposomes for intestinal drug delivery. Int. J. Nanomed. 2018, 13, 5837-5848. [CrossRef]

17. Khalkhali, M.; Mohammadinejad, S.; Khoeini, F.; Rostamizadeh, K. Vesicle-like structure of lipid-based nanoparticles as drug delivery system revealed by molecular dynamics simulations. Int. J. Pharm. 2019, 559, 173-181. [CrossRef] [PubMed]

18. Severino, P.; Pinho, S.C.; Souto, E.B.; Santana, M.H.A. Polymorphism, Crystallinity and hydrophilic-lipophilic balance of stearic acid and stearic acid-capric/caprylic triglyceride matrices for production of stable nanoparticles. Colloids Surf B Biointerfaces 2011, 86, 125-130. [CrossRef]

19. Yang, R.; Gao, R.C.; Cai, C.F.; Xu, H.; Li, F.; He, H.B.; Tang, X. Preparation of gel-core-solid lipid nanoparticle: A novel way to improve the encapsulation of protein and peptide. Chem. Pharm. Bull. 2010, 58, 1195-1202. [CrossRef]

20. Chen, C.; Zhu, X.; Dou, Y.; Xu, J.; Zhang, J.; Fan, T.; Du, J.; Liu, K.; Deng, Y.; Zhao, L.; et al. Exendin-4 loaded nanoparticles with a lipid shell and aqueous core containing micelles for enhanced intestinal absorption. J. Biomed. Nanotechnol. 2015, 11, 865-876. [CrossRef]

21. Xu, Y.; Zheng, Y.; Wu, L.; Zhu, X.; Zhang, Z.; Huang, Y. Novel Solid Lipid Nanoparticle with Endosomal Escape Function for Oral Delivery of Insulin. ACS Appl. Mater. Interfaces 2018, 10, 9315-9324. [CrossRef] [PubMed]

22. Martens, T.F.; Remaut, K.; Demeester, J.; De Smedt, S.C.; Braeckmans, K. Intracellular delivery of nanomaterials: How to catch endosomal escape in the act. Nano Today 2014, 9, 344-364. [CrossRef]

23. Dunn, K.C.; Aotaki-Keen, A.E.; Putkey, F.R.; Hjelmeland, L.M. ARPE-19, A Human Retinal Pigment Epithelial Cell Line with Differentiated Properties. Exp. Eye Res. 1996, 62, 155-170. [CrossRef] [PubMed]

24. Tan, E.; Ding, X.-Q.; Saadi, A.; Agarwal, N.; Naash, M.I.; Al-Ubaidi, M.R. Expression of Cone-Photoreceptor-Specific Antigens in a Cell Line Derived from Retinal Tumors in Transgenic Mice. Investig. Opthalmol. Vis. Sci. 2004, 45, 764. [CrossRef]

25. Huang, L.; Kutluer, M.; Adani, E.; Comitato, A.; Marigo, V. New In Vitro Cellular Model for Molecular Studies of Retinitis Pigmentosa. Int. J. Mol. Sci. 2021, 22, 6440. [CrossRef] [PubMed]

26. Chen, C.; Fan, T.; Jin, Y.; Zhou, Z.; Yang, Y.; Zhu, X.; Zhang, Z.R.; Zhang, Q.; Huang, Y. Orally delivered salmon calcitonin-loaded solid lipid nanoparticles prepared by micelle-double emulsion method via the combined use of different solid lipids. Nanomedicine 2013, 8, 1085-1100. [CrossRef]

27. Vighi, E.; Trifunovic, D.; Veiga-Crespo, P.; Rentsch, A.; Hoffmann, D.; Sahaboglu, A.; Strasser, T.; Kulkarni, M.; Bertolotti, E.; Van Den Heuvel, A.; et al. Combination of cGMP analogue and drug delivery system provides functional protection in hereditary retinal degeneration. Proc. Natl. Acad. Sci. USA 2018, 115, E2997-E3006. [CrossRef]

28. Firdessa, R.; Oelschlaeger, T.A.; Moll, H. Identification of multiple cellular uptake pathways of polystyrene nanoparticles and factors affecting the uptake: Relevance for drug delivery systems. Eur. J. Cell Biol. 2014, 93, 323-337. [CrossRef]

29. Yang, S.T.; Zaitseva, E.; Chernomordik, L.V.; Melikov, K. Cell-penetrating peptide induces leaky fusion of liposomes containing late endosome-specific anionic lipid. Biophys. J. 2010, 99, 2525-2533. [CrossRef]

30. Foroozandeh, P.; Aziz, A.A. Insight into Cellular Uptake and Intracellular Trafficking of Nanoparticles. Nanoscale Res. Lett. 2018, 13, 339. [CrossRef]

31. Kong, B.; Seog, J.H.; Graham, L.M.; Lee, S.B. Experimental considerations on the cytotoxicity of nanoparticles. Nanomedicine 2011, 6, 929-941. [CrossRef]

32. He, C.; Hu, Y.; Yin, L.; Tang, C.; Yin, C. Effects of particle size and surface charge on cellular uptake and biodistribution of polymeric nanoparticles. Biomaterials 2010, 31, 3657-3666. [CrossRef]

33. Kumari, S.; MG, S.; Mayor, S. Endocytosis unplugged: Multiple ways to enter the cell. Cell Res. 2010, 20, 256-275. [CrossRef]

34. Bertolotti, E.; Neri, A.; Camparini, M.; Macaluso, C.; Marigo, V. Stem cells as source for retinal pigment epithelium transplantation. Prog. Retin. Eye Res. 2014, 42, 130-144. [CrossRef] [PubMed]

35. Behzadi, S.; Serpooshan, V.; Tao, W.; Hamaly, M.A.; Alkawareek, M.Y.; Dreaden, E.C.; Brown, D.; Alkilany, A.M.; Farokhzad, O.C.; Mahmoudi, M. Cellular uptake of nanoparticles: Journey inside the cell. Chem. Soc. Rev. 2017, 46, 4218-4244. [CrossRef] [PubMed]

36. Palocci, C.; Valletta, A.; Chronopoulou, L.; Donati, L.; Bramosanti, M.; Brasili, E.; Baldan, B.; Pasqua, G. Endocytic pathways involved in PLGA nanoparticle uptake by grapevine cells and role of cell wall and membrane in size selection. Plant Cell Rep. 2017, 36, 1917-1928. [CrossRef] [PubMed]

37. Arana, L.; Bayón-Cordero, L.; Sarasola, L.; Berasategi, M.; Ruiz, S.; Alkorta, I. Solid Lipid Nanoparticles Surface Modification Modulates Cell Internalization and Improves Chemotoxic Treatment in an Oral Carcinoma Cell Line. Nanomaterials 2019,9 , 464. [CrossRef]

38. Belhadj, S.; Tolone, A.; Christensen, G.; Das, S.; Chen, Y.; Paquet-Durand, F. Long-Term, Serum-Free Cultivation of Organotypic Mouse Retina Explants with Intact Retinal Pigment Epithelium. J. Vis. Exp. 2020, 165, e61868. [CrossRef] 